\title{
Voltando para casa: (re)encontrando Guerreiro Ramos, Trag- tenberg e Prestes Motta
}

\author{
Coming Back Home: Finding Guerreiro Ramos, Tragtenberg And Prestes Motta
}

Sidinei Rocha de Oliveira ${ }^{1}$

Carolina da Silva Ferreira ${ }^{2}$

\section{Resumo}

Este ensaio tem como proposta resgatar alguns aspectos do pensamento de Guerreiro Ramos, de Tragtenberg e de Prestes Motta, destacando como a postura crítica e os questionamentos levantados por esses autores permanecem atuais quando se analisa o papel do pesquisador, a influência da organização burocrática na sociedade atual, a aparente ingenuidade da administração escondida nas harmonias administrativas e no falso participacionismo e a relevância de considerarmos aspectos marcantes da cultura nacional.

O ponto de partida deste texto é a vivência dos autores, que, apesar de diferentes históricos de vida, têm angústias bastante similares ao se moverem no circuito acadêmico e organizacional. Trata-se de um mundo onde existem questionamentos permitidos e temas "relevantes"; onde quem não herda ou não assume a postura de aprendiz - submetendo-se às regras existentes no "caminho para chegar lá" - é continuamente questionado.

Palavras-chave: Guerreiro Ramos; Tragtenberg; Prestes Motta.

Abstract

This essay aims at rescuing some aspects of Guerreiro Ramos, Tragtenberg, and Prestes Motta's thinking. It highlights how the critical posture and questioning of these authors remain updated when one analyzes the role of the researcher, the influence of burocratic organization in present society, the apparent ingenuousness of administration - hidden behind administrative harmonies and fake participation - and the relevance of considering fundamental aspects of the national culture. The starting point for the development of this work is the experience of the authors who, despite having different life stories, share similar anxieties while moving within the academic and organizational circle. $A$ world in which there are allowed questions, "relevant" themes, where those who do not inherit or assume an apprentice's attitude, bowing to the "achiever's rules", are continuously questioned.

Key words: Guerreiro Ramos; Tragtenberg; Prestes Motta.

\footnotetext{
' Doutorando do Programa de Pós-Graduação em Administração - PPGA)/EA/UFRGS. Mestre em Administração PPGA/EA/UFRGS. Endereço:R. Washington Luiz, 855 - Porto Alegre - RS - Brasil - CEP 90010-460. Email: sroliveira@ea.ufrgs.br

${ }^{2}$ Mestranda do Programa de Pós-Graduação em Administração - PPGA/EA/UFRGS. Bióloga pela UFRGS, Endereço:R. Washington Luiz, 855 - Porto Alegre - RS Basil - CEP 90010-460. Email carolbio@terra.com.br

Artigo recebido em agosto de 2006 e aceito para publicação em outubro de 2006.
} 


\section{De onde falamos...}

- Eu sou do Sul, onde os arrozais douram pradarias e o fumo reverdece nos montes. Uma terra em que política, administração e governo adquirem o sentido e os interesses da agricultura. $O$ "bem-estar do povo" está na terra, foi o que ouvi dizer. Porém, na prática, acompanhei grandes fazendeiros revezarem-se na "orientação" dos rumos da cidade, sempre pautando o "bem-estar" da cidade pelo valor que agregavam às suas terras. Cedo vi que esse não era meu lugar. Um espírito urbano num meio rural; não tardei a buscar novos caminhos. Partindo de nosso sistema meritocrático, onde "cada um será recompensado na medida de seu empenho" (Não creio!!) foi o caminho que se apresentou. Mas qual - entre as ciências humanas, exatas e biológicas -, qual caminho a seguir? Na dúvida, como tantos, optei pela administração. Era preciso mudar...

- Quanto a mim, nasci em Porto Alegre e aqui sempre estive. Pelas pradarias e montes também andei, mas já com olhos de "cientista". As inquietações que levaram à escolha da primeira graduação, em ciências biológicas, eram relacionadas às ciências exatas. O "quem somos" e "para onde vamos" contemplavam conjecturas genéticas, fisiológicas e ecológicas. Ao fim do curso, no início do novo milênio, o desejo de "algo mais" levou à busca de outro "nicho", nesse caso, a administração. Acompanhando o senso comum de que "estudar administração" permite fazer qualquer coisa, e ao mesmo tempo consciente da entrada em "outro mundo", o das ciências sociais, (re)comecei o caminho da graduação.

- Já que a dúvida me fez chegar à administração, escolha melhor não poderia ter feito: ciência, arte ou técnica, o "eterno debate" foi o primeiro com que logo me deparei. Mais adiante, um campo de contradições, de lutas, de diferentes abordagens e posicionamentos. Tendo circulado pelo meio acadêmico, direcionei-me para o empresarial. "Afinal, para que serve um administrador longe de uma empresa?" - assim muitas vezes ouvi. Ao circular, ainda muito ingênuo, por grandes organizações, um choque: discurso e prática só andariam juntos se conseguissem maior retorno. Tal como nas fazendas do Sul, as "escolhas humanas" (como diziam) sempre passariam pelo interesse do lucro. Nessa batalha entre pensamento e ação, os valores trazidos de casa foram mais fortes que a pura racionalidade instrumental encontrada. Trabalhar contra aquilo que acreditava, e imagino possível, era violento; nesse caso, autoviolência, não pude aceitar. Não muito tarde, retornei à universidade na esperança de construir algo de acordo com o que acreditava. Enfim, com o mestrado, ergui certezas: é possível fazer algo novo, há espaço para todos; minha voz será ouvida. Fácil caminho a seguir!

- Na graduação em administração, o despertar para a área pública já evidenciou um impulso inicial de tentativa de fuga do lugar-comum. Estando num curso em que tudo é "a empresa", vestir a camiseta da administração pública representa firmar-se como "estrangeiro" e travar constantes embates na velha discussão sobre os limites da mão invisível do mercado ao "mexer" na máquina pública. Antes do fim do curso, o "passo à frente" foi dado e o início do mestrado abriu uma nova etapa. Transitar pelo local onde (em minha concepção) seria possível mudar o "início do processo" era a maior motivação: quem sabe, retornar às salas de aula da graduação tentando quebrar a hegemonia "da empre$s a " ?$

- O caminho que se mostrara tão seguro trouxe inquietações sem resposta: uma guerra por espaço assentada no conhecimento; a reprodução ou a afirmação do meio empresarial sobre a "neutralidade" da academia; a construção do conhecimento restrita à transposição de conceitos e replicação de modelos importados; a troca de gentilezas que impede a discussão e estabelece a livre aceitação de todos os temas sem questionar; todas as vozes serão ouvidas ou isso será uma forma de garantir o diálogo para não mudar. Desolação... será possível mudar?

- É preciso pensar o caráter, muitas vezes vazio, da idéia de "mudança"; isto é, em sua adoção como eterno ciclo de ação ao invés de reflexão. Mudar é preciso! Entretanto, é preciso também pensar "por que", "como" e "para que" estamos mudando. 
Mesmo com trajetórias tão distintas na formação superior e nas experiências profissionais (como anteriormente destacado), nós, estudantes, jovens acadêmicos nos defrontamos com questionamentos similares sobre posturas, atitudes e pensamentos que nos são impostos e cobrados. São esses questionamentos que nos levam ao reencontro de Guerreiro Ramos, Tragtenberg e Prestes Motta como forma de refletir sobre os caminhos apresentados e aqueles que podem ser construídos dentro e fora da academia. A "descoberta" dessa tríade é, - mais do que a consonância de idéias - a possibilidade de resgate e valorização do que foi feito no Brasil sobre os brasileiros, com referência própria, com militância e com crítica situada. Esses autores tornam-se "parceiros" daqueles que estão em busca de seus próprios caminhos na academia e de espaços em que possam dar voz aos seus anseios, debatendo, confrontando idéias e não apenas assumindo modelos que dão continuidade à sempre presente "delinqüência acadêmica".

Este ensaio tem como proposta resgatar alguns aspectos do pensamento de Guerreiro Ramos, Tragtenberg e Prestes Motta, destacando como as idéias trazidas por esses autores permanecem atuais quando se analisa o papel do pesquisador, a influência da organização burocrática na sociedade atual, a ingenuidade da administração escondida nas harmonias administrativas e no falso participacionismo, bem como a relevância de considerarmos aspectos marcantes da cultura nacional. O ponto de partida para o desenvolvimento deste estudo é nossa vivência, que, apesar de diferentes históricos de vida, leva-nos a angústias bastante similares quando nos movemos no circuito acadêmico e organizacional. Um mundo onde existem questionamentos permitidos, temas "relevantes", onde quem não herda ou não assume a postura de aprendiz, submetendo-se às regras existentes no "caminho para chegar lá", é continuamente questionado.

\section{$\boldsymbol{I}$}

Tal como Guerreiro Ramos já apontava no início da década de 1960, tanto a pesquisa quanto o ensino (e mesmo a prática) da administração seguem, em grande parte, restritos à simples repetição dos conceitos desenvolvidos por autores estrangeiros, sem levar em consideração a realidade socioeconômica do Brasil. Nesse sentido, o avanço do trabalho sociológico (e hoje da administração) não deve ocorrer pela sua produção de caráter reflexo, mas, pela fundamentação na ciência dos fatores infraestruturais que a influenciam. Esse avanço deve constituir-se como um conhecimento "por fazer", e, para que se consolide como área de referência, é preciso que seja construído considerando-se sua ligação com a realidade em que se encontra. Essa forma de pensar requer do pesquisador um esforço muito maior que a mera aquisição de informação especializada; exige uma capacidade analítica que vai além da ciência em hábito, pois configura-se numa ciência em ato, uma forma de pesquisa que requer maior engajamento com as questões sociais vivenciadas por aqueles que as conduzem (RAMOS, 1996).

Assim, Guerreiro Ramos propõe a redução sociológica como um método crítico-assimilativo, fundamentado no trabalho de um intelectual consciente de sua realidade social, e atento à tarefa de fundamentação teórica da cultura nacional. O pesquisador brasileiro deve levar em conta que a redução sociológica:

- é um procedimento metódico que procura tornar sistemática a assimilação crítica;

- não admite a existência de uma realidade social sem pressupostos;

- está vinculada a uma determinada visão de mundo;

- considera que o contexto determinado em que os objetos se encontram, em parte, os constitui;

- tem seus aportes coletivos, não, individuais;

- é uma atitude altamente elaborada, embora seus suportes sejam vivências populares (RAMOS, 1996, p.7273). 


\section{II}

Ao contrário do que propõe Guerreiro Ramos, no campo dos estudos de administração, acompanha-se o aumento do número de pesquisas voltadas para a internacionalização das empresas, na tentativa de compreender novas culturas e como empresas nacionais atuam em outras nações. No entanto, como entender a forma de atuar das empresas nacionais em outros países se poucos são os estudos voltados para a realidade nacional?

Qual a realidade nacional? Considerando os estudos em administração, estes estariam voltados para o Brasil? Num país onde predominam pequenas e médias empresas, por que prevalecem os estudos sobre multinacionais? A formação e o crescimento das multinacionais acaba por criar "um tipo de profissional desvinculado das lealdades nacionais e familiares, um tipo 'desterritorializado', cuja lealdade fundamental é com a organização" (MOTTA, 1990, p.95). Da mesma forma, o interesse principal dessas organizações é buscar matéria-prima e mão-de-obra onde houver menor custo, produzir onde houver maiores incentivos, com o único objetivo de maximizar lucros. Voltar a atenção para as multinacionais é contribuir para um estudo sem território, que deixa de atender a qualquer realidade nacional e destina-se apenas a atender às demandas do mercado financeiro.

Para Guerreiro Ramos, a teoria da organização centrada no mercado não pode ser aplicada a todos, mas apenas a alguns tipos de atividades. A generalização desses princípios dificultaria a modernização de sistemas sociais, impedindo a superação de dilemas básicos da sociedade. Assim, o autor busca apresentar uma nova forma de estruturação das organizações e de relacionamento com os demais grupos sociais que se contraponha ao sistema centrado no mercado - baseado na racionalidade funcional e contaminado pela síndrome comportamentalista -, que levaria os indivíduos a internalizarem os comportamentos organizacionais, transpondo-os para outras realidades sociais.

\section{III}

No que se refere aos pesquisadores da administração, prevalece a afirmação da neutralidade científica, sem interesses. Baseado no discurso da ciência tradicional, que opõe a "verdade" à "ideologia", o saber neutro não permitiria erros, garantindo uma verdadeira apreensão da realidade. No entanto, é cada vez mais evidente que a universidade utiliza o discurso do saber neutro, apolítico e objetivo para camuflar suas contradições de classe, nas quais a sociedade se mantém (TRAGTENBERG, 1990). Acobertada por essa pretensa neutralidade, é possível acompanhar a reafirmação da "multiversidade" em que as instituições de ensino têm se transformado. Embora ainda existam as universidades públicas, onde a graduação, o mestrado e o doutorado são gratuitos, sabe-se que mesmo estas têm se rendido à lógica de mercado: os cursos de especialização, genericamente chamados de $M B A s$, adquirem importância central, uma vez que deles vem grande parte do dinheiro que possibilita melhorar as condições de trabalho, os prédios e os equipamentos das universidades, a quais seguem penando no recebimento de verbas governamentais para se manterem. Talvez, essa necessidade de manutenção justifique, em parte, a atenção que esses cursos têm recebido, mas pode-se questionar se os interesses que existem por trás da maioria dos alunos que buscam essa especialização não estão muito mais estreitamente vinculados ao recebimento de um título como possibilidade de promoção do que ao interesse pela reflexão ou pelo desenvolvimento de algum projeto de vida. O nível de pós-graduação adquire importância central na formação da mão-deobra destinada a manter o despotismo do capital nas empresas.

A mercantilização do ensino tem transformado professores em "máquinas de ensinar", simples reprodutores de técnicas e ferramentas com as quais os alunos atingiriam melhores resultados na administração. Algumas faculdades, com a intenção de "uniformizar o currículo" em suas diversas sedes, não só determinam os conteúdos - pelos programas de ensino que entregam aos professores -, como também enviam apresentações onde já está determinado o que deve ser ensinado.

Seria a taylorização do ensino? A separação do pensar e do executar na preparação da aula? Aqueles que seguem corretamente todas as regras ou transformam suas aulas em espetáculos circenses, espetáculos onde a platéia aplaude os exemplos práticos explorados pelo showman - sem preocupação se algum dia isto vai fazer parte de sua realidade - têm espaço garantido. A universidade segue reproduzindo o "modo de produção capitalista dominante, não apenas pela ideologia que transmite, mas pelos servos que forma". (TRAGTENBERG, 1990, p.14). Esse modo de produção determina o tipo de formação por meio das mudanças adotadas na escola. 
Na relação entre mestres e estudantes, o professor segue como um cão pastor responsável pelo direcionamento da formação dos alunos, enquanto estes são meros expectadores. Sem questionar, estes buscam apenas preparar-se para a "realidade" que irão encontrar nas empresas.

Ao bom seguidor de regras, o exemplo de conduta está reservada à possibilidade de assumir funções de coordenação nos cursos, quando passam de professores a controladores de números e resultados, pressionando aqueles que não alcançam suas metas. Buscam atender às metas de aprovação, de não-evasão, de satisfação dos "alunos-clientes", sem se preocuparem com a contribuição que podem estar dando à formação dos alunos em sala de aula. Aos professores-coordenadores, tecnocratas do ensino, também está reservada uma nova função: vendedores! São eles os responsáveis por procurar no mercado um número suficiente de alunos que garanta a "lucratividade" do curso. Dessa forma, proliferam as faculdades de administração em todo o país. O argumento principal: ainda existe mercado!

\section{IV}

"Em congressos sobre negócios, o congresso também é o negócio". Nossos encontros de pós-graduação seguem servindo de "mercado humano" (TRAGTENBERG, 1990, p.17), onde mais importante que a contribuição dos estudos é a necessidade de "ver e ser visto", de manter e ampliar contatos, de manter a "empregabilidade" e garantir o mercado, uma vez que a estabilidade não é mais um luxo dos docentes. Há um "expressivo investimento" para apresentar trabalhos a si mesmos ou aos "parceiros": o jogo de cavalheirismos esmaga a possibilidade de crítica e análise do que está sendo publicado. Uma vez que todo o sistema passa a ser regido pelo imperativo da quantidade, pouco importando o conteúdo e a qualidade do que se publica (o que vale é a pontuação), porque perder tempo discutindo o que é apresentado, já que esse tempo é fundamental para mais e mais publicações? E além do mais, se todos estão voltados para seus próprios trabalhos, quem lerá os artigos publicados?

Congressistas se isolam em "fortificações de luxo" que os abrigam e "proporcionam" dias de reclusão em "nãolugares": hotéis de padrão internacional! Na verdade, estes são espaços sem identidade que definem o território da "discussão cientifica", separando-os das referências locais de onde o congresso é realizado. Nesse cenário em que o espaço externo é invisível, presenciamos situações tragicômicas, como a de assistir pela imensa janela envidraçada um funcionário, sem nenhuma proteção, jogar veneno em ervas daninhas, ao mesmo tempo em que se assiste uma sessão de gestão ambiental. O incômodo da situação é rapidamente justificado: "trata-se de um terceirizado!". A posição que o indivíduo ocupa ou seu vínculo com a organização serão a justificativa para assumir um descompromisso com a "verdade" que incomoda? Vidro, tijolos e aço não são a maior barreira a ser transposta.

Existem aqueles que questionarão essa visão do mundo acadêmico, apontando que está permeada por um excessivo pessimismo: "Não é visível o crescimento do número dos ditos trabalhos críticos?". Mas tal como Tragtenberg refere, se existe crítica, é uma crítica no nível do que é aceitável, uma crítica domesticada que garante espaço para aqueles que se supõem críticos sem que estes interfiram nos trabalhos dos outros, uma crítica que tem por função tranqüilizar os que questionam as contribuições do meio universitário à sociedade.

Antes de tudo, uma análise critica requer uma atitude de reflexão, de assumir um posicionamento e uma postura de compromisso com o trabalho que está sendo desenvolvido.

Uma teoria crítica das organizações aceita totalmente as conseqüências políticas de sua ação, escolhe submeter a inquérito racional a situação existente, acusa as instituições que servem de apoio às classes no poder, liga-se ao empenho político de uma análise rigorosa dos mecanismos e das forças que regulam o funcionamento da sociedade; mecanismos e forças que sempre refletirão a diversidade de práticas sociais múltiplas, sem a consideração da qual a vida cultural e social pode fazer sentido (MOTTA, 1990, p. 18). 
A universidade segue como mais uma instituição onde se afirma a estrutura de classes, onde está claramente definido quem manda e quem obedece, onde o saber configura poder. Enquanto isso, busca-se um maior número de publicações e uma representativa participação nos congressos, que se multiplicam anualmente e que, para muitos, têm como função principal "ver e ser visto". Os próprios alunos também se tornam agentes fomentadores desse sistema - influenciados por valores que enfatizam o individualismo, a competição e a autoridade -, em detrimento da coletividade, da solidariedade e da liberdade, por um saber formal-burocrático, não um conhecimento reflexivo e coletivamente construído.

Formatados desde a educação infantil por procedimentos que reforçam a estrutura burocrática e opressora do ensino, os alunos têm dificuldades de assumir sua posição como sujeitos capazes de vivenciar o processo educativo, de desenvolver uma atitude reflexiva e de estabelecer uma relação não-autoritária com seus professores.

Ao saírem da graduação, especialmente da administração, esses alunos irão constituir as organizações contemporâneas, instituições que seguem afirmando a divisão de classes e que, embora garantam a possibilidade de ascensão, reservam essa possibilidade para aqueles que, além de mais produtivos, também servem de exemplo de dedicação às normas e aos objetivos da empresa.

Como quebrar esse ciclo? Como garantir a possibilidade de transformação? Tragtenberg acredita que cada professor não precisa ser um simples reprodutor de conceitos preso ao autoritarismo narcísico, mas alguém que goste de aprender, estudar e compartilhar. Ser professor é viver uma prática em que "o mestre possui um saber inacabado e o aluno, uma ignorância transitória; não há saber absoluto nem ignorância absoluta." (2005, p.14).

\section{VII}

Desde o início da era industrial, a administração amplia continuamente seu domínio no cenário mundial. Espaços antes comandados pela Igreja, pelos Estados e exércitos dão lugar à influência das grandes corporações. O pensamento baseado nos resultados (na pura racionalidade instrumental) não está mais restrito ao limite da fábrica, pois abrange escolas, hospitais e até igrejas. Cada vez mais o objetivo principal de qualquer organização tem se pautado apenas pelo lucro, onde os trabalhadores representam "peças" a serem adaptadas ao bom funcionamento da grande engrenagem. Ao mesmo tempo, é reforçada a ideologia que garante a contínua reprodução de idéias, afirma a igualdade e que cada indivíduo terá seu "sucesso" vinculado apenas ao próprio esforço. Dessa forma, garante como idéias hegemônicas aquelas que reforçam a permanência dos mesmos interesses e dos mesmos "vitoriosos".

A burocratização, tal como alertou Prestes Motta (1990; 1994), atinge todos os setores da vida social: a economia, a política, a cultura, a saúde e o lazer. A sociedade moderna transformou-se numa sociedade de organizações burocráticas submetidas a outras organizações burocráticas: o Estado, os órgãos de relações internacionais etc. Nessa sociedade, predomina uma população assalariada, integrada pela estrutura de cargos a organizações impessoais, onde o trabalho perde seu significado e se busca manter o emprego em troca de segurança e conformismo. Os interesses e necessidades dos indivíduos são manipulados para aumentar o consumo e o desejo de ter. As organizações passam a ser o centro da vida social e, mesmo organizações que se dizem democráticas (como partidos, sindicatos e cooperativas), estão presas ao modelo burocrático (MOTTA, 1994). Atrelados e protegidos por seus cargos e conhecendo como funciona a estrutura, os indivíduos abandonam a participação ativa na vida social e passam a se defender e a fugir da responsabilidade de suas ações, atrelando isso à "neutralidade" de seu cargo.

Em busca de "transformação", novas propostas de organização têm surgido, tais como cooperativas, organizações de economia solidária e ONGs, que, embora tenham trazido inicialmente a idéia de uma forma de atuação diferente, têm se mostrado mera reprodução do "modelo empresarial", subordinando-se a este. Tal como alertou Prestes Motta (1990; 1994), permanece o modelo burocrático, mascarado de eficiente e impessoal, constituindo uma reformulação e um reforço ao capitalismo, pois dentro e fora dessas organizações prevalecem as relações de poder baseadas nas diferenças de classe. A burocracia permanece como forma de amenizar o conflito latente entre dominantes e dominados, possi- 
bilitando que todos acreditem participar ativamente da construção dos rumos da organização e do bem-estar da sociedade. Crentes de sua participação, permanecem alienados, distanciando-se ainda mais de qualquer possibilidade de mudança e de real atuação (MOTTA, 1990).

\section{VIII}

Da valorização dos grupos sociais de Mayo, passando pela contínua procura da participação dos funcionários nas decisões da organização, pelo comprometimento organizacional e (mais recentemente) pelo estímulo ao voluntariado em favor da empresa, seguem as contínuas reconfigurações das estruturas organizacionais em busca das harmonias administrativas (TRAGTENBRERG, 1992), negando as contradições internas na organização. O conflito de classes é mascarado por representações simbólicas (o bem comum, a coletividade, a "família organizacional" etc.).

Um das grandes preocupações da era industrial não se restringe à superação do conflito, mas à sua antecipação, para desenvolver modos de controle que possam negar a estrutura de classes nela subjacente. Nascem as "empresas com alma", onde o trabalhador é chamado a vestir a camisa e participar, e que nada mais são do corporações que procuram compatibilizar lucro com "função social" (TRAGTENBRERG, 2005, p.17). Nesse sentido, os trabalhadores estabelecem uma forte identificação com os objetivos da organização, que, desse modo, antecipa e evita o conflito. A ideologia busca, então, legitimar a ação da organização, mascarando os objetivos de dominação em nome da colaboração que se estabelece entre seus integrantes e sua contribuição para o coletivo. Dessa forma, constitui-se a face alienante da burocracia (MOTTA, 1994).

\section{Reflexões... o caminho só começa}

Partindo de publicações, congressos e debates na Administração, percebemos que o trabalho do pesquisador e do administrador brasileiro permanece, em grande parte, reduzido a simples importação e aplicação de conceitos.

A repetição, confirmação e reprodução de idéias oriundas de outras realidades, sem considerar o contexto nacional, tornam-se as principais deficiências da produção acadêmica brasileira na atualidade. A continuidade dessa forma de pensar, trabalhar e fazer pesquisa faz com que mesmo os novos entrantes no mundo acadêmico assumam sua "delinqüência" (TRAGTENBERG, 1990), sem pensar, questionar e assumir a responsabilidade pelas idéias que defendem. Aceitar esse caminho implica negar parte da história acadêmica nacional. Significa não reconhecer, ou considerar como "pensamento isolado", o trabalho de autores como Tragtenberg, Guerreiro Ramos e Prestes Motta, que defendiam a crítica à teoria das organizações e negavam a pretensa neutralidade da pesquisa científica, defendendo acadêmicos politizados, engajados e responsáveis por sua produção, na busca por uma teoria da administração voltada para a realidade brasileira.

Das suas contribuições, destacam-se os questionamentos sobre o caráter passivo-assimilativo ainda característico da produção acadêmica brasileira. Para nós, novos entrantes no campo dos estudos organizacionais, a mera reprodução de conceitos, a herança de linhas de pesquisa já aceitas e o seguir as "regras do jogo" sem questionar pode parecer o caminho mais fácil a ser percorrido. Contudo, essa escolha significa aceitar tacitamente a submissão a muitas das verdades já postas, garante um espaço no mundo acadêmico, mas muitas vezes se restringe a abandonar diferentes formas de pensar, a simplesmente buscar um espaço sem ter compromisso com o que é produzido. É aceitar servilmente uma posição passiva no jogo de poder e interesses do campo cientifico, implica assumir para si a responsabilidade pelas consequiências de seus estudos e os motivos que conduziram a elas. Mais do que isso, herdar é ter a garantia do descompromisso de criar algo seu, menos preocupação com uma reflexão teórica séria, escondendo-se atrás da replicação de modelos e pensamentos importados.

A proposta deste ensaio de resgatar elementos importantes do pensamento crítico de Guerreiro Ramos, Tragtenberg e Prestes Motta para os estudos organizacionais brasileiros não deve ser vista como um trabalho fechado, como mais um artigo que após publicado servirá para contar nos indicadores dos programas e somar-se a outros em nossos currículos Lattes. Antes de tudo, é um chamado ao engajamento e ao resgate desses autores que trouxeram contribuições fundamentais para a compreensão das organizações nacionais. Suas obras, muito 
mais do que reflexões teóricas, trazem a postura de um pesquisador crítico: um caráter reflexivo sobre os temas propostos, uma posição firme e engajada, além de responsável e comprometida em dar uma contribuição para o desenvolvimento do país.

Busquemos o desenvolvimento de uma ciência em ato, consciente de nossos posicionamentos e disposta a assumir as consequiências de seus resultados. Não nos deixemos dominar pelo caminho tranqüilo da "delinquiência acadêmica" que restringe, limita e enfraquece as possibilidades de construção de algo que realmente esteja ligado a nossa realidade; que está preocupada com o status de títulos, estabilidade em instituições ou volume de produção. Enfim, assumamos que não existe verdade sem ideologia e que fazemos parte de um campo de lutas onde podemos assumir uma função de atores, ao invés de contemplarmos como meros figurantes os embates que ocorrem. Por mais que pareça utópico ou distante, deve-se ter claro que é possível existir uma realidade diferente, onde haja mais engajamento, respeito e comprometimento com o outro. Acreditar que não há espaço para mudança é prender-se ao conformismo e render-se ao pensamento dominante. 


\section{Referências:}

MOTTA, Fernando Claudio Prestes. Organização e poder: empresa, Estado e escola. São Paulo: Atlas, 1990. 0 que é burocracia. São Paulo: Brasiliense, 1994.

RAMOS, Alberto Guerreiro. A redução sociológica. Rio de Janeiro: UFRJ, 1996.

TRAGTENBERG, M.. Sobre educação, política e sindicalismo. São Paulo: Cortez, 1990. Burocracia e ideologia. São Paulo: Ática, 1992.

Administração, poder e ideologia. São Paulo: Unesp, 2005. 